BULLETIN OF THE

AMERICAN MATHEMATICAL SOCIETY

Volume 80, Number 5, September 1974

\title{
HARRY SCHULTZ VANDIVER, 1882-1973
}

\author{
BY D. H. LEHMER
}

This remarkable man was born in Philadelphia, Pennsylvania on October 21,1882 . He was self-taught in his youth and must have had little patience with secondary education since he never graduated from high school. This impatience, especially with mathematical education, was to last the rest of his life.

He showed an early interest in the theory of numbers when he began solving problems in the American Mathematical Monthly in 1900. In 1904 he and the twenty year old, G. D. Birkhoff, collaborated in the unconscious rediscovery of an important theorem of A. S. Bang (1886) on the characteristic prime factors of $a^{n}-b^{n}$. This paper in the Annals of Mathematics was one of the first of his list of 174 publications. While serving as an agent in his father's business, he began attending lectures at the Graduate School of the University of Pennsylvania and reading algebraic number theory, especially the papers of Kummer on cyclotomic fields and Fermat's Last Theorem. By the year 1917, when he began active duty in the Naval Reserve, he had published a dozen papers on the distribution of power residues and the Fermat problem. His work of this period caught the attention of Landau; in fact, the latter's definitive three volume Vorlesungen über Zahlentheorie (1927) contains no other American name.

After World War I Vandiver decided to become a professional mathematician and joined the staff of the Cornell Mathematics Department as an instructor. In 1924 he accepted an Associate Professorship at the University of Texas where he spent the rest of his academic career. In 1966 , at the age of 84 , health reasons forced his retirement from his modified service appointment as Professor of Applied Mathematics and Astronomy.

Vandiver was awarded the Cole Prize in 1931 for his papers on the Fermat problem. In 1934-1935 he served as Vice-President of the American Mathematical Society and was elected at this time to the National Academy of Science. A majority of his 120 papers since then have appeared in its Proceedings. In 1935 he gave the Colloquium Lectures at Ann Arbor on the Fermat problem. Although his name is usually associated with this problem, his interest and publications ranged over a much wider set of subjects. These included cyclotomic and abelian fields, Bernoulli numbers, 
reciprocity laws, finite fields, factorization methods, semigroups and semirings and constructive theory of algebras.

His work on the Fermat problem was not aimed directly at the complete solution for all values of $p$ in the equation

$$
x^{p}+y^{p}+z^{p}=0
$$

but rather it was an effort to develop stronger criteria, for the most part involving only $p$, from the basic work of Kummer. When practical, these criteria were tested to show that (1) was impossible for $p \leqq L$, with $L$ increasing slowly over the years. Impractical criteria were compared, combined, or set aside for possible future use. His early work involved criteria for the so-called first case of (1) in which $p$ does not divide $x y z$. Very strong criteria exist in this case which result in very large values of $L$. (Today we know that $L$ can be taken as $3 \cdot 10^{9}$.) Vandiver in later years often expressed the view that a complete solution of the first case was to be expected soon. The second case, where $p$ divides $x$, is perhaps unexpectedly difficult and its criteria are less effective. Before the advent of automatic computing, Vandiver and his students had pushed the value of $L$ into the six hundreds. In his seventies he was able to modify his criteria for implementation on high speed computers. As a result, $L$ has now been set at 25,000 .

In spite of Vandiver's intense concern with his own research and that of his many graduate students, he found time to write expository papers, and to do editing, refereeing, reviewing and committee work. A notable instance of this latter activity is the 1923 Report on the theory of algebraic numbers, National Research Council Bulletin no. 28, with L. E. Dickson, H. H. Mitchell and G. E. Wahlin, a "Dickson type" history of the subject.

Vandiver's best method of communicating ideas was that of personal face to face discussion; he was a poor lecturer. In these discussions he conveyed not only the mathematical ideas, but also his ideas about mathematics. These were often strong and well put and reminded one of his contemporary, E. T. Bell. During such a session it was not unusual to have him inject his opinions about other topics such as baseball and Mozart. He was a man of many parts with a great mind of his own.

Department of Mathematics, University of California, Berkeley, California 94720 